\title{
Review
}

\section{The role of microvessel density on the survival of patients with lung cancer: a systematic review of the literature with meta-analysis}

\section{A-P Meert*,', M Paesmans', B Martin', P Delmotte', T Berghmans', J-M Verdebout ${ }^{3}$, J-J Lafitte ${ }^{4}$, C Mascaux' and J-P Sculier'}

\author{
'Département de Médecine Interne et Laboratoire d'Investigation Clinique et d'Oncologie Expérimentale HJ Tagnon, Institut Jules Bordet, Bruxelles, Belgium: \\ ${ }^{2}$ Data Centre, Institut Jules Bordet, Bruxelles, Belgium; ${ }^{3}$ Senvice d'Anatomo-Pathologie, Institut Jules Bordet, Bruxelles, Belgique; ${ }^{4}$ Senvice de Pneumologie \\ et d'Oncologie Thoracique, CHU Calmette, Lille, France
}

In order to determine whether angiogenesis is a prognostic marker in lung cancer, we performed a systematic review of the literature to assess the prognostic value on survival of microvessel count in patients with lung cancer. Published studies were identified by an electronic search in order to aggregate survival results, after a methodological assessment using a quality scale designed by the European Lung Cancer Working Party. To be eligible, a study had to deal with microvessel count assessment in lung cancer patients on the primary site and to provide survival analysis according to microvessel count expression. Microvessel count has been assessed on surgical samples by immunohistochemistry using factor VIII in I4 studies, CD34 in I0 and CD31 in eight. Respectively 1866, I440 and 1093 non-small cell lung cancer patients were considered. The overall median quality scores were respectively 52, 59 and 59\% for studies assessing microvessel count via factor VIII, CD34 and CD31, without significant difference between studies evaluable or not for meta-analysis nor between studies with significant or non significant results. Seven 'factor VIII' studies, nine 'CD34' and seven 'CD3I' provided sufficient data allowing a metaanalysis on survival and were evaluable for results aggregation. This showed that a high microvessel count in the primitive lung tumour was a statistically significant poor prognostic factor for survival in non small cell lung cancer whatever it was assessed by factor VIII (HR: I.8I; 95\% Cl: I.16-2.84), CD34 (HR: I.99; 95\% Cl: I.53-2.58) or CD3। (HR: I.80; 95\% Cl: I.10-2.96). Variations in survival among the individual studies can be explained in addition to patients selection criteria by the heterogeneous methodologies used to stain and count microvessels: different antibody clones, identification of 'hotspots', Weidner or Chalkey counting method, cut-off selection. Microvessel count, reflecting the angiogenesis, appears to be a poor prognostic factor for survival in surgically treated non small cell lung cancer but standardisation of angiogenesis assessment by the microvessel count is necessary.

British Journal of Cancer (2002) 87, 694-701. doi:I0.1038/sj.bjc.660055 I www.bjcancer.com

(C) 2002 Cancer Research UK

Keywords: lung cancer; microvessel count; microvessel density; meta-analysis

Lung cancer is the most common cause of death by malignancy in industrialised countries. Less than $15 \%$ of the patients will be cured and enjoy long-term survival. This poor prognosis can be modulated by characteristics related to the patient or the tumour. These prognostic factors can be used for different purposes such as a better understanding of the natural history of the disease or the identification of homogeneous patient's populations with a similar outcome profile. Some independent clinical and biological predictors have been identified for predicting survival (Paesmans and Sculier, 1998): for resectable non small cell lung cancer (NSCLC) age, performance status and TNM stage (Strauss, 1997). Among routine biological factors, serum lactate dehydrogenase, white blood cell and neutrophil count have been shown to

*Correspondence: Dr AP Meert, Institut Jules Bordet, I, rue Héger Bordet, 1000-Bruxelles, Belgium; E-mail: ap.meert@bordet.be

Received 25 April 2002; revised 19 July 2002; accepted 25 July 2002 significantly predict survival in NSCLC (Kanters et al, 1995). Recent developments in cytogenetic and molecular biology have provided new ways to analyse prognosis. Biological substaging using molecular markers in a risk stratification strategy has been proposed. Tumour suppressor genes, proto-oncogenes, markers of proliferation and angiogenesis are some of the different research tools.

Angiogenesis is the formation of new blood vessels from the endothelium of the existing vasculature. These new capillaries arise from pre-existing capillaries or venules and represent the consequence of the growth of columns of aligned endothelial cells. Adjacent columns contact to form loops, which then develop a lumen. Neo-angiogenesis is fundamental in tumour growth, progression and metastases and there is now experimental evidence to indicate that tumour growth is dependent on angiogenesis (Folkman, 1990). After a new tumour has attained a small size of 1-2 mm, further growth and expansion of the tumour require the induction of new blood vessels. Although this angiogenesis 
alone is not sufficient for developing metastases, new blood vessel formation increases the opportunity for malignant cells to enter the blood stream and thus the development of metastases (Weidner et al, 1991). Newly formed capillaries are permeable because of fragmented basement membranes, making them more accessible to errant tumour cells (Weidner et al, 1992).

Tumour angiogenesis is a complex multifactor process involving growth factor and extracellular matrix enzymes. A variety of proteins such as the vascular endothelial growth factor, the platelet-derived endothelial cell growth factors and the basic fibroblast growth factor released by tumour and stroma cells have been recognised to be potent inducers of angiogenesis (Bikfalvi et al, 1997; Ishikawa et al, 1989; Ferrara, 2000).

Recent evidence suggests that tumour angiogenesis is associated with patient outcome in a number of malignancies. Microvessel density seems to be an important prognostic indicator in lung cancer (Fontanini et al, 1995; Giatromanolaki et al, 1997) although some studies have not found microvessel count to be predictive for survival (Chandrachud et al, 1997; Pastorino et al, 1997). Currently, different antibodies to three endothelial cell antigens can be used to visualise the tumour blood vessels by immunohistochemistry: factor VIII antigen or von Willebrand's factor is involved in platelet adhesion and aggregation; CD31 or PECAM 1 (platelet/endothelial cell adhesion molecule) is associated with platelet adhesion in inflammation, wound healing, trans-endothelial cell migration and cell migration; CD34 is involved in leukocyte adhesion and endothelial cell migration during angiogenesis.

In order to determine whether microvessel count is a prognostic factor for survival in lung cancer patients, we performed a systematic review of the literature with methodological assessment.

\section{MATERIALS AND METHODS}

\section{Publication selection}

To be eligible for this review, trials had to deal with lung cancer only, to evaluate the correlation between microvessel count and survival, to measure the microvessel count in the primary tumour (not in metastatic tissue or in tissue adjacent to the tumour) and to be published as a full paper in the English or French language literature. Abstracts were excluded from this analysis because of insufficient data to apply the scoring system and to evaluate the methodological quality of the trial.

Articles were identified by an electronic search on Medline using the keywords lung neoplasms, CD31, PECAM-1, CD34, factor VIII, angiogenesis, neoangiogenesis, angiogenic factor, neovascularisation, microvessel, vessel density, vascular density or microvascular density. The bibliographies reported in all the identified studies were used for completion of the trials search. When authors reported, in several publications, on the same patients populations, only the most recent or complete study was included into the analysis, in order to avoid overlapping between cohorts. The search ended on September 2001.

\section{Methodological assessment}

In order to assess the methodology, each trial was read and scored according to the ELCWP (European Lung Cancer Working Party) scale by nine investigators (including six physicians, one pathologist, one biologist and one biostatistician). Consensual agreement on the scores attributed to each item for each trial was obtained during meetings where the participation of many readers was a guarantee for the correct interpretation of the articles. The scoring system used in this literature review has already been described in one of our prior systematic reviews (Steels et al, 2001). The overall score assessed many dimensions of methodology, grouped in four main categories: the scientific design, the description of the laboratory methods used to quantify MVC, the generalisability of the results and the analysis of the study data. Each category had a maximal score of 10 points with an overall maximal theoretical score of 40 points. The final scores were expressed as percentages, higher values reflecting a better methodological quality. Studies included in the systematic review were called 'eligible' and those providing sufficient data for the meta-analysis 'evaluable'.

\section{Statistical methods}

A study was considered as significant if the $P$ value for the statistical test comparing survival distributions between the groups with and without high microvessel count was $<0.05$ in univariate analysis. The study was called 'positive' when a high microvessel count was identified as a significant favourable prognostic factor for survival. The study was called 'negative' if the same characteristic was associated with a significant detrimental effect on survival. Finally, a study was called 'not significant' if no statistical difference between the two groups was detected.

The association between two continuous variables was measured by the Spearman ranks correlation coefficient. Mann - Whitney test was used to compare the distribution of the quality scores according to the value of a binary variable.

If it was possible, we dichotomised the variable MVC by using the observed median.

For the quantitative aggregation of survival results, we measured the impact of microvessel count on survival by the hazard ratio (HR) between the two survival distributions. For each trial, this HR was estimated by a method depending on the data provided in the publications. The most accurate method consisted of calculating the estimated HR and its standard error using two of the following parameters: the HR point estimate, the logrank statistic or its $P$ value, the O-E statistic (difference between numbers of observed and expected events) or its variance. If those data were not available, we looked for the total number of events, the number of patients at risk in each group and the logrank statistic or its $P$ value allowing calculation of an approximation of the HR estimate. Finally, if the only available data were in the form of graphical representations of the survival distributions, we extracted from them survival rates at some specified times in order to reconstruct the HR estimate and its variance, with the assumption that the rate of patients censored was constant during the study follow-up (Parmar et al, 1998). If this last method was used, three independent persons read the curves to reduce the imprecision in the reading variations. The individual HR estimates were combined into an overall HR using Peto's method (Yusuf et al, 1985), which consisted of using a fixed effect model assuming homogeneity of the individual true HRs. This assumption was tested by performing $\chi^{2}$ tests for heterogeneity. If the assumption of homogeneity had to be rejected, we used a random-effects model as a second step. By convention, an observed HR $>1$ implied a worse survival for the group with a high microvessel count. This pejorative impact of angiogenesis on survival was considered as statistically significant if the $95 \%$ confidence interval for the overall HR did not overlap 1.

\section{RESULTS}

\section{Studies selection and characteristics}

Twenty-one studies detecting MVC by factor VIII were selected. Seven of the articles (Angeletti et al, 1996; Fontanini et al, 1996, 1997b, 1998a; Harpole et al, 1996; Takanami et al, 1999; D'Amico et al, 2000) were excluded because identical cohorts of patients were included in other selected publications. 
In the 14 remaining eligible studies (Macchiarini et al, 1994; Yamazaki et al, 1994; Fontanini et al, 1995; Mattern et al, 1995; Chandrachud et al, 1997; Giatromanolaki et al, 1997; Takanami et al, 1997; Duarte et al, 1998; Imoto et al, 1998; Aikawa et al, 1999; D'Amico et al, 1999; Ohta et al, 1999; Sheng et al, 2000; Yano et al, 2000), published between 1994 and 2000, the total number of patients was 1866 ranging from 28 to 408. The main characteristics of these 14 studies are shown in Table 1. Twelve of them dealt with NSCLC whatever the histologic subtype considered and two with adenocarcinoma only. Ten studies concerned only limited disease and four all stages (I to IV). Different antibodies were used to assess factor VIII positivity.

CD34 was used in 13 studies. Three of the articles (Lucchi et al, 1997; Fontanini et al, 1998b; Cox et al, 2000) were excluded because identical cohorts of patients were included in other publications. In the 10 remaining eligible studies (Fontanini et al, 1997a; Matsuyama et al, 1998; Shibusa et al, 1998; Dazzi et al, 1999; Cagi- ni et al, 2000; Takanami et al, 2000; Yano et al, 2000; Cox et al, 2001; Liao et al, 2001; Offersen et al, 2001), published between 1997 and 2001, the total number of included patients was 1440 ranging from 44 to 407 patients by trial. The main characteristics of these 10 eligible studies are shown in Table 2. Eight of them dealt with NSCLC whatever the histologic subtype considered and two with adenocarcinoma only. Nine studies concerned only limited stage disease and one, all stages. Most of the time, clone QB-END 10 monoclonal antibody was used to assess CD 34 immunoreactivity.

In terms of CD31 detection, 18 studies were selected. Ten were excluded (Giatromanolaki et al, 1996a,b, 1997, 2000a,b; Koukourakis et al, 1997, 1999, 2000a,b; Kakolyris et al, 1999) because identical cohorts of patients were used in other selected publications. In the eight remaining eligible studies (Apolinario et al, 1997; Kawaguchi et al, 1997; Pastorino et al, 1997; Duarte et al, 1998; Ohta et al, 1999; O'Byrne et al, 2000; Han et al, 2001; Hasegawa et al, 2001), published between 1996 and 2001, the total

Table I Main characteristics and results of the eligible studies evaluating the microvessel count by factor VIII

\begin{tabular}{|c|c|c|c|c|c|c|c|c|}
\hline Author & Year & Histology & Stage & $n$ & HR estimation & Results & Cut-off & Antibody \\
\hline Yamazaki et al & 1994 & Adenoc & I-IV & 42 & No data & NS & Arbitrary & Dako Po Ab \\
\hline Macchiarini et al & 1994 & NSCLC & $|-|||$ & 28 & No data & Negative & Median & Dako Mo Ab \\
\hline Fontanini et al & 1995 & NSCLC & $|-||| B$ & 248 & Survival curves & Negative & Median & Dako \\
\hline Mattern et al & 1995 & NSCLC & $|-|||$ & 204 & Survival curves & NS & Mean & Dako \\
\hline Takanami et al & 1997 & Adenoc & I-IV & 120 & Survival curves & Negative & Arbitrary & Nichirei Mo Ab \\
\hline Chandrachud et al & 1997 & NSCLC & $|-||| A$ & 88 & Logrank & NS & Median & Dako A0082 \\
\hline Giatromanolaki et al & 1997 & NSCLC & $|-| \mid$ & 134 & No data & Negative & Arbitrary & Dako Mo F8/86 \\
\hline Duarte et al & 1998 & NSCLC & 1 & 96 & Survival curves & Negative & Mean & Ventana Mo Ab \\
\hline Imoto et al & 1998 & NSCLC & $|-||| B$ & 91 & $\mathrm{HR}+\mathrm{Cl}$ & NS & Mean & Dako Po A0082 \\
\hline D'Amico et al & 1999 & NSCLC & 1 & 408 & Logrank & Negative & Arbitrary & Biogenex Mo Ab \\
\hline Aikawa et al & 1999 & NSCLC & $|-||| B$ & 97 & No data & Negative & Arbitrary & TaKaRa Mo Ab \\
\hline Ohta et al & 1999 & NSCLC & I & 104 & No data & Negative & Mean & Dako Po Ab \\
\hline Yano et al & 2000 & NSCLC & I-IV & 108 & No data & NS & Median & Dako Mo Ab \\
\hline Sheng et al & 2000 & NSCLC & I-IV & 98 & No data & $\mathrm{NC}$ & Median & Santa Cruz \\
\hline
\end{tabular}

NSCLC=non-small cell lung cancer; $n=$ number of patients; $\mathrm{HR}+\mathrm{Cl}=$ hazard ratio+confidence interval; Results=author's results; Adenoc=adenocarcinoma; Cut-off=cut-off for positivity; NS=not significant; NC=not conclusive; Mo Ab=monoclonal antibody; Po Ab=polyclonal antibody. These abbreviations also apply to Tables 2 and 3.

Table 2 Main characteristics and results of the eligible studies evaluating the microvessel count by CD34

\begin{tabular}{|c|c|c|c|c|c|c|c|c|}
\hline Author & Year & Histology & Stage & $n$ & HR estimation & Results & Cut-off & Antibody \\
\hline Fontanini et al & $1997 \mathrm{a}$ & NSCLC & $|-|||$ & 407 & Logrank & Negative & Median & Clone QB END 10 \\
\hline Shibusa et al & 1998 & Adenoc & | & 44 & Survival curves & Negative & Mean & Clone QB END 10 \\
\hline Matsuyama et al & 1998 & NSCLC & $|-||| B$ & 101 & Logrank & Negative & Mean & Clone QB END 10 \\
\hline Dazzi et al & 1999 & NSCLC & |-|||B & 76 & Logrank & NS & Median & Clone QB END 10 \\
\hline Cagini et al & 2000 & NSCLC & I-IIB & 99 & Logrank & NS & Median & Clone QB END 10 \\
\hline Takanami et al & 2000 & Adenoc & $|-||| A$ & 180 & Survival curves & Negative & Mean & Novocastra Mo Ab \\
\hline Yano et al & 2000 & NSCLC & I-IV & 108 & Logrank & Negative & Median & Clone QB END 10 \\
\hline Liao et al & 2001 & NSCLC & $|-|||$ & 115 & No data & NS & Arbitrary & No data \\
\hline Offersen et al & 2001 & NSCLC & $|-|||$ & 143 & Survival curves & NS & Median & Clone QB END 10 \\
\hline Cox et al & 2001 & NSCLC & $|-||| A$ & 167 & $\mathrm{HR}+\mathrm{Cl}$ & Negative & Median & Clone QB END 10 \\
\hline
\end{tabular}

Table 3 Main characteristics and results of the eligible studies evaluating the microvessel count by CD3I

\begin{tabular}{|c|c|c|c|c|c|c|c|c|}
\hline Author & Year & Histology & Stage & $n$ & HR estimation & Results & Cut-off & Antibody \\
\hline Ohta et al & 1999 & NSCLC & I & 15 & Logrank & Negative & Mean & Dako Mo Ab \\
\hline Kawagushi et al & 1997 & Adenoc & 1 & 42 & Survival curves & Negative & Median & Clone JC70 \\
\hline Apolinario et al & 1997 & NSCLC & $|-||| A$ & 104 & Survival curves & Negative & Median & Clone JC70 \\
\hline Pastorino et al & 1997 & NSCLC & 1 & 515 & $\mathrm{HR}+\mathrm{Cl}$ & NS & Median & Clone JC70 \\
\hline Duarte et al & 1998 & NSCLC & i & 96 & Survival curves & NS & Median & Dako Mo Ab \\
\hline O'Byrne et al & 2000 & NSCLC & $\| \mathrm{A}$ & 183 & Survival curves & Negative & Arbitrary & Clone JC70 \\
\hline Han et al & 2001 & NSCLC & । & 85 & Survival curves & Negative & Arbitrary & Ventana \\
\hline Hasegawa et al & 2001 & NSCLC & $|-|||$ & 53 & No data & NS & Mean & Clone JC70 \\
\hline
\end{tabular}


number of included patients was 1093 ranging from 15 to 515 patients by trial. The main characteristics of the eight studies eligible for the systematic review are shown in Table 3. Seven of them dealt with NSCLC whatever the histologic subtype and one with adenocarcinoma only. Seven studies concerned only limited stage disease and one all stages diseases. In five studies, JC70 monoclonal antibody was used to detect CD31.

For the three antibodies, immunoreactivity was always assessed on surgical samples.

\section{Studies results reports}

When factor VIII was used to assess MVC, eight studies reported 'negative' results, five were not significant and one was not conclusive. Seven studies were evaluable for meta-analysis.

Looking at the survival results in the studies dealing with CD34, six studies were 'negative' and four were not significant. Nine studies were evaluable for meta-analysis.

When CD31 was detected, five studies were 'negative' and three not significant. Seven were evaluable for meta-analysis.

\section{Quality assessment}

Concerning 'factor VIII' studies, the overall quality score ranged from $36.2 \%$ to $72.9 \%$ with a median of $52.4 \%$. The 'design' subscore had the lowest value (median: $30 \%$ ). There was no statistically significant quality difference between evaluable and nonevaluable studies for meta-analysis (median overall scores: $68.1 \%$ vs $49.6 \%, P=0.07)$. No statistically significant quality difference was shown between significant and non-significant trials (median overall scores $49.7 \%$ vs $56.9 \%, P=0.73$ ).

For 'CD34' studies, the overall quality score ranged from $43.3 \%$ to $76.3 \%$ with a median of $59.3 \%$. The 'design' subscore had the lowest median value $(40 \%)$. No statistically significant quality difference was shown between the significant and the non-significant trials (median overall scores $63.6 \%$ vs 59.2\%, $P=0.67)$.

For 'CD31' studies, the overall quality score ranged from $38.9 \%$ to $72.9 \%$ with a median of $59.5 \%$. The 'design' subscore had the lowest median value $(45 \%)$. No statistically significant quality difference was shown between the significant and the non-significant trials (median overall scores $53.2 \%$ vs $69.9 \%$, $P=0.17)$.
There was no significant correlation between quality scores and the number of patients included in the studies or with the date of publication of the studies.

\section{Meta-analysis}

The absence of significant quality difference between significant and non-significant studies allowed us to perform a quantitative aggregation of the survival results.

Among the 32 trials eligible for the systematic review evaluating MVC with factor VIII, nine could not be included in the metaanalysis due to insufficient data to estimate the HR or because data concerned only some subgroups of patients. The hazard ratios of the 23 evaluable studies were calculated by one of the three methods reported in the Materials and methods section. Hazard ratio and $95 \%$ confidence intervals were published in three trials. They were approximated from the logrank statistic and the number of events in eight studies. Finally, the HR and its variability had to be extrapolated from the graphical representations of the survival distributions in the 12 others. With a fixed-effect model, the HR was 1.71 (95\% CI: $1.44-2.04)$ for factor VIII studies, $1.95(95 \%$ CI: $1.65-2.30)$ for CD34 studies and 1.40 (95\% CI: $1.17-1.63$ ) for CD31 studies. However, the test of heterogeneity was significant for factor VIII $(P<0.001)$, CD34 $(P=0.02)$ and CD31 studies $(P=0.004)$. Thus, we calculated the HR using a random-effects model and obtained a value which was statistically significant for factor VIII HR: 1.81 (95\% CI: 1.16-2.84) (Figure 1), for CD34 1.99 (95\% CI: 1.53-2.58) (Figure 2) and for CD31 HR: 1.80 (95\% CI: 1.10-2.96) (Figure 3).

\section{DISCUSSION}

In this systematic review, by pooling all the studies comparing survival of lung cancer patients according to the angiogenic activity of the tumour, as expressed by the MVC, we show that a high MVC is a poor prognosis factor for survival in surgical NSCLC whatever the antibody used for assessment of the vessel count. This observation is potentially important for prognostic reasons and treatment purposes. Angiogenesis assessment might be useful not only in stratifying patients for different (adjuvant) treatment regimens but also in predicting their response to chemotherapy (Koukourakis, 2001; Mattern, 2001), to anti-angiogenic therapies and identifying the precancerous lesions (Pazouki et al, 1997).

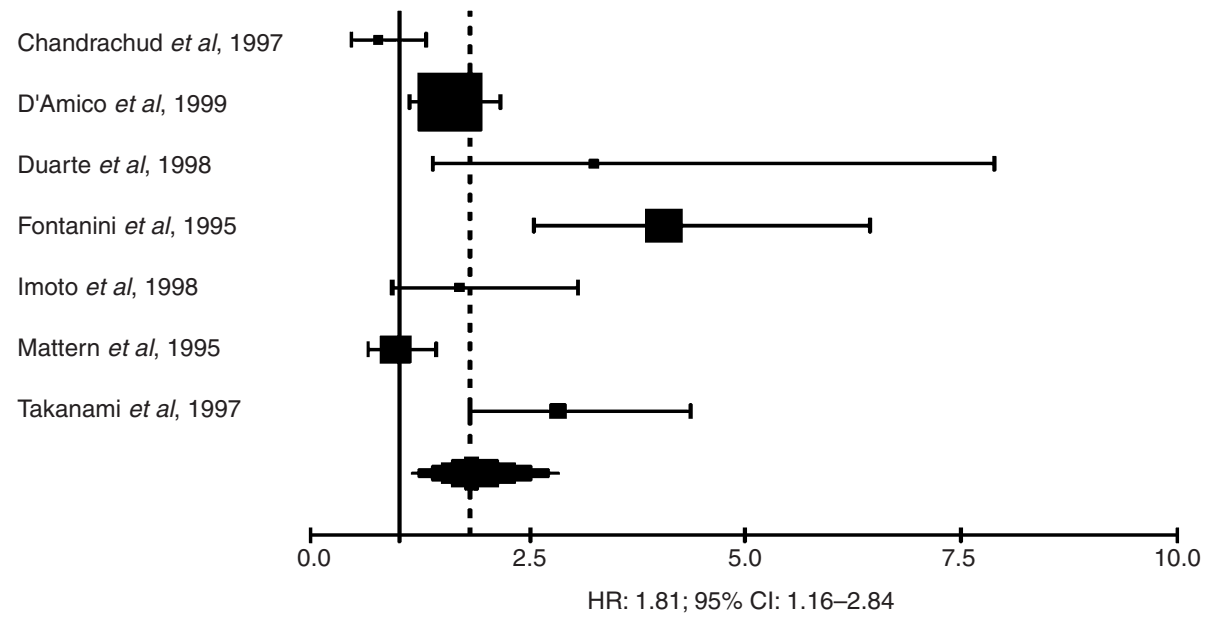

Figure I Results of the meta-analysis of the studies using factor VIII. HR > I implies a survival disadvantage for the group with a high microvessel count. The square size is proportional to the number of patients included in the study. The centre of the lozenge gives the combined HR for the meta-analysis and its extremities the $95 \%$ confidence interval. 


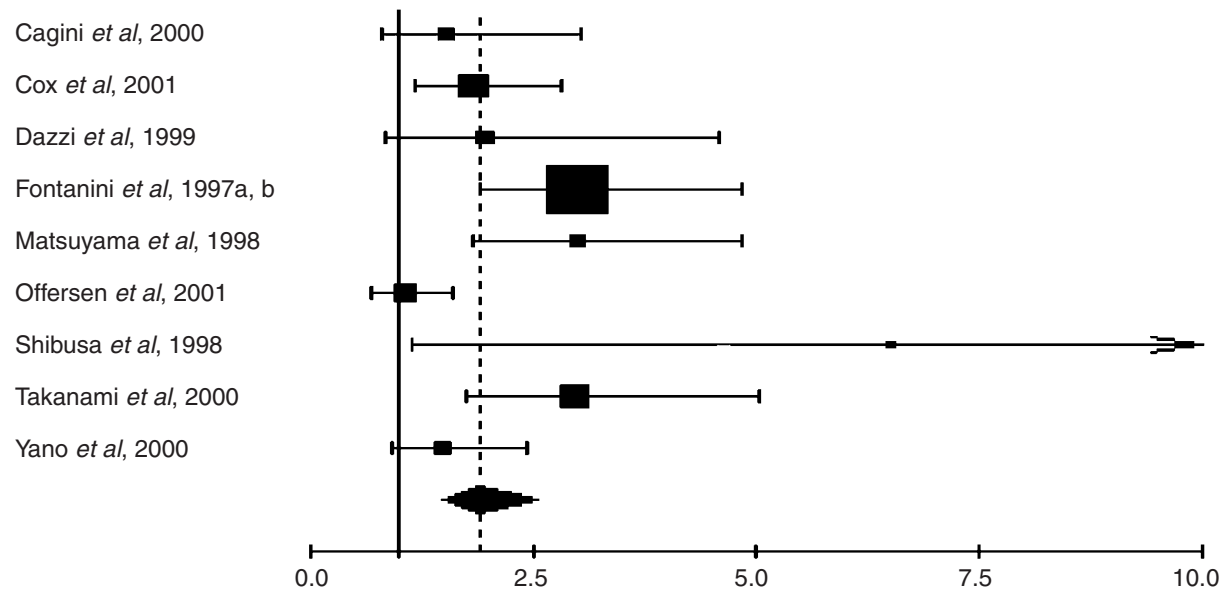

HR: $1.99 ; 95 \% \mathrm{Cl}: 1.53-2.58$

Figure 2 Results of the meta-analysis of the studies using CD34.

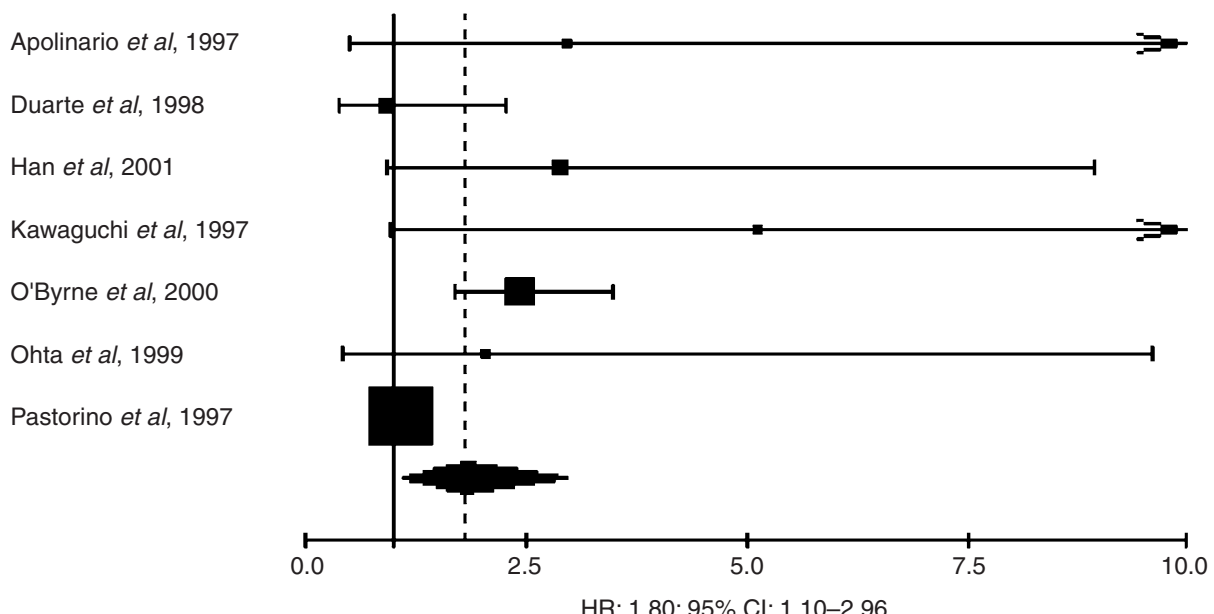

HR: $1.80 ; 95 \% \mathrm{Cl}: 1.10-2.96$

Figure 3 Results of the meta-analysis of the studies using CD31.

It is also to be noted that the trials published on the topic concerned NSCLC treated, at least, by surgery; we could thus not extrapolate our results to metastatic NSCLC or small cell lung cancer.

To perform the meta-analysis, we have used a methodology similar to previous systematic reviews of our group on the treatment of lung cancer (Meert et al, 1999) but adapted to the field of biological prognostic factors (Steels et al, 2001). The absence of statistically significant difference in quality score between significant and non-significant publications allowed us to perform a quantitative aggregation of the individual trials results.

Our approach does not however prevent all potential biases. We restricted our review to articles published in French or English language because other languages such as Japanese were not accessible to the readers. This selection could favour the positive studies that are more often published in English while the negative ones tend to be more often reported in native languages (Egger et al, 1997). Another possible source of confusion is the use of a same cohort of patients in different publications. It might be difficult to avoid the same patients being included more than once in the meta-analysis. We have excluded publications where it seemed to be the case after writing to some of the authors in order to have more information on patients' cohort, a procedure that was unsuc- cessful: we had only one partial response. Harris confirmed that there were an overlapping of the same patients in the series of Giatromanolaki, Koukourakis et al The method of extrapolation of HRs also needs to be discussed. When HRs were not reported by the authors, they were calculated from the data reported in the article and, if not available, extrapolated from the survival curves, implying assumptions on the censoring process. This approach might also have been associated with errors due to imprecision in the reading, although three independent persons read the curves to reduce the reading variation.

Our review took into account only fully published studies. We did not look for unpublished trials and abstracts because our methodology required data available in full publications only. Meta-analysis based on individual data is considered by some authors as a gold standard (Stewart and Parmar, 1993). Systematic reviews of the literature should not be confused with meta-analyses of individual patient data. The first approach is based on fully published studies and provides an exhaustive and critical analysis on the topic with an adequate methodology based on the criteria of Mulrow (1987). The second approach is, in fact, a new study taking into account all performed studies on the topic, published or not, requiring individual data update by the investigators and is much more time-consuming. Nevertheless, as shown by our 
meta-analysis on the role of prophylactic cerebral irradiation in small-cell lung cancer (Meert et al, 2001), based on published data, we obtained the same results as in the meta-analysis based on individual data (Auperin et al, 1999).

Variations in survival results among the studies could be explained by the heterogeneity in methodologies used to stain and count microvessels in the tumours in addition to variation in patients population. The estimated vascularity in tissues sections can be significantly affected by variations in the applied methodology including pre-treatment and antibody use. The vessels in tumour samples can be identified by some different endothelial cell-specific antibodies: most often recognising factor VIII, CD31 or CD34 related antigen. Factor VIII (Von Willebrand's factor) was one of the first marker used for staining microvessels but it may be imprecise to quantify microvasculature for various reasons. Firstly, factor VIII is not expressed in all endothelial cells. The microvessels endothelial cells are less rich in Weibel-Palade bodies, which store factor VIII, than the endothelial cells of macrovessels (and the endothelial cells of neocapillaries may be activated by cytokines releasing their factor VIII stores). Secondly, factor VIII is also present in lymphatic endothelium and in platelets leading to a cross-reactivity with megakaryocytes, platelets and lymphatic endothelial cells. CD34, a heavily glycosylated transmembrane protein, is expressed on immature human haematopoietic precursor cells and is progressively lost during maturation. It is also present in the luminal endothelial membrane. CD34 is more sensitive and specific than factor VIII for staining endothelial cells induced by tumour neovascularisation (Tanigawa et al, 1996) but could also stain some lymphatic vessels. Only specific antibodies (i.e. LYVE 1, VEGF-C) can be used to detect lymphatics and not blood vessels. Anti-CD34 antibody seems to be more reliable in terms of specificity and reproducibility than monoclonal antibodies generated against other endothelial cell antigens (Tanigawa et al, 1996). In invasive breast cancer, CD34 has been shown to yield higher microvessel values than CD31 or factor VIII (Martin et al, 1997) and does not stain any tumour or inflammatory cells as CD31 or factor VIII. CD31 is a transmembrane glycoprotein highly expressed in mature and immature endothelium and its localisation at the endothelial cell junctions suggests an important role in transendothelial migration. CD31 is expressed during myelomonocytic cellular differentiation and consequently may cross-react with plasma cells, platelets, neutrophils, peripheral $\mathrm{T}$ cells and mantle zone B cells; endothelial staining can be easily differentiated on the basis of the morphological differences. JC70 antibody stains also CD31 positive lymphocytes that could be a prognostically important inflammatory component in lung cancer (Giatromanolaki et al, 1997). For some authors, CD31 seems to be the most sensitive marker for the endothelial cells and consistently stains more vessels than did factor VIII (Horak et al, 1992). An international consensus on the methodology and criteria of evaluation of microvessel density proposed that anti-CD31 monoclonal antibody should be the standard for microvessel assessment (Vermeulen et al, 1996) as it is superior on paraffin sections. But as CD34 has been shown to yield higher microvessel values than CD31 or factor VIII in breast cancer (Martin et al, 1997), it might be useful to combine CD34 and CD31 antibodies. In lung cancer, Offersen et al (2001) compared the staining with these three antibodies. $\mathrm{He}$ found that CD34 showed the best labelling of the endothelial cells and no background staining (data not shown). Yano et al (2000) found that correlation between factor VIII and CD34 staining for MVC was not strong and that staining for CD 34 significantly correlated with survival in adenocarcinoma but staining for factor VIII did not. Duarte et al (1998) reported that CD 31 did not predict survival in stage I NSCLC and did not correlate strongly with factor VIII which is correlated with lung cancer death. Giatromanolaki et al (1997) concluded that CD31 is sensitive for highlighting small, immature microvessels and is better correlated with nodal involvement and overall survival than factor VIII. Unfortunately, data were not sufficient to compare the three antibodies by a meta-analysis methodology.

Contradictory results in the literature may also be explained by variations in vascularity between areas in different sections from the same block or among blocks taken from the same tumour (de Jong et al, 1995) and by the methods used to measure vascularity (Pazouki et al, 1997). In large tumours, it could be necessary to examine multiple blocks in order to determine the overall vascularity of the tumour. Identifying the area of maximal microvessel density seems to be an important step in the counting method (Vermeulen et al, 1997) as tumour dissemination is more likely to occur at sites of high microvessel density. In lung cancer, the border between malignant and benign tissues is often blurred by atelectases, fibrosis and inflammatory cells, making the problem more difficult. The difficulty in recognising the vascular 'hotspots' may account for studies that failed to find an association between MVC and poor patients survival.

The technique used to count the microvessels is also different among the articles. Most of the studies used a technique similar to that proposed by Weidner et al (1991). The areas of highest neovascularization ('hotspots') is found by scanning the tumour sections at low power $(40 \times$ and $100 \times)$ and then individual microvessels are counted on a $200 \times$ and $400 \times$ field. Each count is expressed as the highest number of microvessels identified within any $200 \times$ or $400 \times$ field. This technique is slow and laborious. A eye piece graticule (as a 25-point Chalkey graticule) has also been applied for vascular scoring in patients with NSCLC (Giatromanolaki et al, 1996a). In breast cancer, Fox et al (1995) showed that Chalkey counting is a rapid and objective method of quantifying tumour angiogenesis and gives independent prognostic information. A proposition of consensus identified the Chalkey method as slightly more objective (Vermeulen et al, 1996). We did not perform aggregation of the results in term of microvessel counting technique because the techniques were too heterogeneous.

Moreover, there is no standardised cut-off used for stratifying patients into high and low vascular groups. Some authors used the MVC median or the MVC mean and others the 'best cutoff, which is often arbitrary defined or chosen using multiple tests with a corresponding increase in the probability of founding a false positive results. The selection of the median value of the expression levels is a standard approach to analyse new prognostic factors, even if it may lead to some loss of information.

Assessment of tumour vascularity by immunohistochemistry on paraffin-embedded tissues can be easily performed in laboratory but standardisation of angiogenesis quantification is necessary in order to better define its prognostic value (Vermeulen et al, 1996) and to facilitate a routine use.

In conclusion, a high $\mathrm{MVC}$, reflecting tumour neoangiogenesis, is a poor survival prognostic factor for NSCLC surgically treated patients. These results were based on an aggregation of data obtained by univariate survival analysis in retrospective trials. In order to become an useful prognostic factor, a standardisation of angiogenesis quantification is necessary and the present results need to be confirmed by an adequately designed prospective study with an appropriate multivariate analysis taking into account the classical well defined prognostic factors for lung cancer.

\section{ACKNOWLEDGEMENTS}

This research was supported by the 'FNRS' and by 'Les Amis de l'Institut Bordet'. A-P Meert is a Research Fellow FNRS. 


\section{REFERENCES}

Aikawa H, Takahashi S, Fujimura S, Sato M, Endo C, Sakurada A, Kondo T, Tanita T, Matsumura Y, Ono S, Saito Y, Sagawa M (1999) Immunohistochemical study on tumor angiogenic factors in non-small cell lung cancer. Anticancer Res 19: 4305-4310

Angeletti CA, Lucchi M, Fontanini G, Mussi A, Chella A, Ribechini A, Vignati S, Bevilacqua G (1996) Prognostic significance of tumoral angiogenesis in completely resected late stage lung carcinoma (stage IIIA-N2). Cancer 78: $409-415$

Apolinario RM, van der Valk P, de Jong JS, Deville W, Ark-Otte J, Dingemans AM, van Mourik JC, Postmus PE, Pinedo HM, Giaccone G (1997) Prognostic value of the expression of p53, bcl-2, and bax oncoproteins, and neovascularization in patients with radically resected non-small-cell lung cancer. J Clin Oncol 15: 2456-2466

Auperin A, Arriagada R, Pignon JP, Le Pechoux C, Gregor A, Stephens RJ, Kristjansen PE, Johnson BE, Ueoka H, Wagner H, Aisner J (1999) Prophylactic cranial irradiation for patients with small-cell lung cancer in complete remission. Prophylactic Cranial Irradiation Overview Collaborative Group. N Engl J Med 341: 476-484

Bikfalvi A, Klein S, Pintucci G, Rifkin DB (1997) Biological roles of fibroblast growth factor-2. Endocr Rev 18: 26-45

Cagini L, Monacelli M, Giustozzi G, Moggi L, Bellezza G, Sidoni A, Bucciarelli E, Darwish S, Ludovini V, Pistola L, Gregorc V, Tonato M (2000) Biological prognostic factors for early stage completely resected non- small cell lung cancer. J Surg Oncol 74: 53-60

Chandrachud LM, Pendleton N, Chisholm DM, Horan MA, Schor AM (1997) Relationship between vascularity, age and survival in non-small-cell lung cancer. $\mathrm{Br} J$ Cancer 76: $1367-1375$

Cox G, Jones JL, Andi A, Waller DA, O’Byrne KJ (2001) A biological staging model for operable non-small cell lung cancer. Thorax 56: $561-566$

Cox G, Walker RA, Andi A, Steward WP, O’Byrne KJ (2000) Prognostic significance of platelet and microvessel counts in operable non-small cell lung cancer. Lung Cancer 29: 169-177

D’Amico TA, Aloia TA, Moore MB, Herndon JE, Brooks KR, Lau CL, Harpole Jr DH (2000) Molecular biologic substaging of stage I lung cancer according to gender and histology. Ann Thorac Surg 69: 882-886

D’Amico TA, Massey M, Herndon JE, Moore M-B, Harpole DH (1999) A biologic risk model for stage I lung cancer: immunohistochemical analysis of 408 patients with the use of ten molecular markers. J Thor Cardiovasc Surg 117: $736-743$

Dazzi C, Cariello A, Maioli P, Solaini L, Scarpi E, Rosti G, Lanzanova G, Marangolo M (1999) Prognostic and predictive value of intratumoral microvessels density in operable non-small-cell lung cancer. Lung Cancer 24: $81-88$

de Jong JS, van Diest PJ, Baak JP (1995) Heterogeneity and reproducibility of microvessel counts in breast cancer. Lab Invest 73: $922-926$

Duarte IG, Bufkin BL, Pennington MF, Gal AA, Cohen C, Kosinski AS, Mansour KA, Miller JI (1998) Angiogenesis as a predictor of survival after surgical resection for stage I non-small-cell lung cancer. J Thor Cardiovasc Surg 115: $652-659$

Egger M, Zellweger-Zahner T, Schneider M, Junker C, Lengeler C, Antes G (1997) Language bias in randomised controlled trials published in English and German. Lancet 350: 326-329

Ferrara N (2000) VEGF: an update on biological and therapeutic aspects. Curr Opin Biotechnol 11: 617-624

Folkman J (1990) What is the evidence that tumors are angiogenesis dependent? J Natl Cancer Inst 82: 4-6

Fontanini G, Bigini D, Vignati S, Basolo F, Mussi A, Lucchi M, Chinè S, Angeletti CA, Harris AL, Bevilacqua G (1995) Microvessel count Predicts metastatic disease and survival in non-small cell lung cancer. J Pathol 117: $57-63$

Fontanini G, Boldrini L, Vignati S, Chinè S, Basolo F, Silvestri V, Lucchi M, Mussi A, Angeletti CA, Bevilacqua G (1998a) Bcl2 and p53 Regulate Vascular Endothelial growth Factor (VEGF)-mediated Angiogenesis in Non-small Cell Lung Carcinoma. Eur J Cancer 34: 718-723

Fontanini G, De Laurentis M, Vignati S, Chinè S, Lucchi M, Silvestri V, Mussi A, De Placido S, Tortora P, Raffaele Bianco A, Gullick W, Angeletti CA, Bevilacqua G, Ciardello F (1998b) Evaluation of epidermal growth factor-related growth factors and receptors and of neoangiogenesis in completely resected stage I-IIIA non-small-cell lung cancer: amphiregulin and microvessel count are independent prognostic indicators of survival. Clin Cancer Res 4: $241-249$
Fontanini G, Lucchi M, Vignati S, Mussi A, Ciardello F, De Laurentis M, De Placido S, Basolo F, Angeletti CA, Bevilacqua G (1997a) Angiogenesis as a prognostic indicator of survival in non-small-cell lung carcinoma: a prospective study. J Natl Cancer Inst 89: $881-886$

Fontanini G, Vignati S, Bigini D, Mussi A, Lucchi M, Chinè S, Angeletti CA Bevilacqua G (1996) Recurrence and death in non-small cell lung carcinomas: a prognostic model using pathological parameters, microvessel count, and gene protein products. Clin Cancer Res 2: $1067-1075$

Fontanini G, Vignati S, Lucchi M, Mussi A, Calcinai A, Boldrini L, Chinè S, Silvestri V, Angeletti CA, Basolo F, Bevilacqua G (1997b) Neoangiogenesis and p53 protein in lung cancer: their prognostic role and their relation with vascular endothelial growth factor (VEGF) expression. $\mathrm{Br} \mathrm{J}$ Cancer 75: $1295-1301$

Fox SB, Leek RD, Weekes MP, Whitehouse RM, Gatter KC, Harris AL (1995) Quantitation and prognostic value of breast cancer angiogenesis: comparison of microvessel density, Chalkley count, and computer image analysis. J Pathol 177: 275-283

Giatromanolaki A, Koukourakis MI, O’Byrne KJ, Fox S, Whitehouse RM Talbot DC, Harris AL, Gatter KC (1996a) Prognostic value of angiogenesis in operable non-small cell lung cancer. $J$ Pathol 179: $80-88$

Giatromanolaki A, Koukourakis MI, O’Byrne KJ, Kaklamanis L, Dicoglou C Trichia E, Whitehouse RM, Harris AL, Gatter KC (1996b) Non-small cell lung cancer: c-erbB-2 overexpression correlates with low angiogenesis and poor prognosis. Anticancer Res 16: 3819-3826

Giatromanolaki A, Koukourakis MI, Sivridis E, O’Byrne K, Cox G, Thorpe PE, Gatter KC, Harris AL (2000a) Coexpression of MUC1 glycoprotein with multiple angiogenic factors in non-small cell lung cancer suggests coactivation of angiogenic and migration pathways. Clin Cancer Res 6: $1917-1921$

Giatromanolaki A, Koukourakis MI, Sivridis E, O’Byrne K, Gatter KC, Harris $\mathrm{AL}$ (2000b) 'Invading edge vs. inner' (edvin) patterns of vascularization: an interplay between angiogenic and vascular survival factors defines the clinical behaviour of non-small cell lung cancer. J Pathol 192: 140-149

Giatromanolaki A, Koukourakis MI, Theodossiou D, Barbatis K, O’Byrne K, Harris AL, Gatter KC (1997) Comparative evaluation of angiogenesis assessment with anti-factor-VIII and anti-CD31 immunostaining in nonsmall cell lung cancer. Clin Cancer Res 3: 2485-2492

Han H, Silverman JF, Santucci TS, Macherey RS, d'Amato TA, Tung MY, Weyant RJ, Landreneau RJ (2001) Vascular endothelial growth factor expression in stage I non-small cell lung cancer correlates with neoangiogenesis and a poor prognosis. Ann Surg Oncol 8: $72-79$

Harpole DH, Richards WG, Herndon JE, Sugarbaker DJ (1996) Angiogenesis and molecular biologic substaging in patients with stage I non-small cell lung cancer. Ann Thorac Surg 61: 1470-1476

Hasegawa Y, Takanashi S, Kanehira Y, Tsushima T, Imai T, Okumura K (2001) Transforming growth factor-betal level correlates with angiogenesis, tumor progression, and prognosis in patients with nonsmall cell lung carcinoma. Cancer 91: 964-971

Horak ER, Leek R, Klenk N, LeJeune S, Smith K, Stuart N, Greenall M, Stepniewska K, Harris AL (1992) Angiogenesis, assessed by platelet/endothelial cell adhesion molecule antibodies, as indicator of node metastases and survival in breast cancer. Lancet 340: $1120-1124$

Imoto H, Osaki T, Taga S, Ohgami A, Ichiyoshi Y, Yasumoto K (1998) Vascular endothelial growth factor expression in non-small-cell lung cancer: prognostic significance in squamous cell carcinoma. J Thor Cardiovasc Surg 115: $1007-1014$

Ishikawa F, Miyazono K, Hellman U, Drexler H, Wernstedt C, Hagiwara K, Usuki K, Takaku F, Risau W, Heldin CH (1989) Identification of angiogenic activity and the cloning and expression of platelet-derived endothelial cell growth factor. Nature 338: $557-562$

Kakolyris S, Giatromanolaki A, Koukourakis MI, Leigh IM, Georgoulias V Kanavaros P, Sivridis E, Gatter KC, Harris AL (1999) Assessment of vascular maturation in non-small cell lung cancer using a novel basement membrane component, LH39: correlation with p53 and angiogenic factor expression. Cancer Res 59: $5602-5607$

Kanters SD, Lammers JW, Voest EE (1995) Molecular and biological factors in the prognosis of non-small cell lung cancer. Eur Respir J 8: 1389-1397

Kawaguchi T, Yamamoto S, Kudoh S, Goto K, Wakasa K, Sakurai M (1997) Tumor angiogenesis as a major prognostic factor in stage I lung adenocarcinoma. Anticancer Res 17: 3743 - 3746 
Koukourakis MI (2001) Tumour angiogenesis and response to radiotherapy. Anticancer Res 21(6B): 4285-4300

Koukourakis MI, Giatromanolaki A, Guddo F, Kaklamanis L, Vignola M, Kakolyris S, Turley H, Georgoulias V, Bonsignore G, Gatter KC, Harris AL (2000a) c-erbB-2 and episialin challenges host immune response by HLA class I expression in human non-small-cell lung cancer. J Immunother 23: $104-114$

Koukourakis MI, Giatromanolaki A, O'Byrne KJ, Cox J, Krammer B, Gatter KC, Harris AL (1999) bcl-2 and c-erbB-2 proteins are involved in the regulation of VEGF and of thymidine phosphorylase angiogenic activity in non-small-cell lung cancer. Clin Exp Metastasis 17: 545-554

Koukourakis MI, Giatromanolaki A, O’Byrne KJ, Whitehouse RM, Talbot DC, Gatter KC, Harris AL (1997) Potential role of bcl-2 as a suppressor of tumour angiogenesis in non-small-cell lung cancer. Int J Cancer 74: $565-570$

Koukourakis MI, Giatromanolaki A, Thorpe PE, Brekken RA, Sivridis E, Kakolyris S, Georgoulias V, Gatter KC, Harris AL (2000b) Vascular endothelial growth factor/KDR activated microvessel density versus CD31 standard microvessel density in non-small cell lung cancer. Cancer Res 60: $3088-3095$

Liao M, Wang H, Lin Z, Feng J, Zhu D (2001) Vascular endothelial growth factor and other biological predictors related to the postoperative survival rate on non-small cell lung cancer. Lung Cancer 33: 125-132

Lucchi M, Fontanini G, Mussi A, Vignati S, Ribechini A, Menconi GF, Bevilacqua G, Angeletti CA (1997) Tumor angiogenesis and biologic markers in resected stage I NSCLC. Eur J Cardio-thor Surg 12: 535-541

Macchiarini P, Fontanini G, Dulmet E, de Montpreville V, Chapelier AR, Cerrina J, Le Roy Ladurie F, Dartevelle PG (1994) Angiogenesis: an indicator of metastasis in non-small cell lung cancer invading the thoracic inlet. Ann Thorac Surg 57: 1534-1539

Martin L, Green B, Renshaw C, Lowe D, Rudland P, Leinster SJ, Winstanley J (1997) Examining the technique of angiogenesis assessment in invasive breast cancer. Br J Cancer 76: $1046-1054$

Matsuyama K, Chiba Y, Sasaki M, Tanaka H, Muraoka R, Tanigawa N (1998) Tumor angiogenesis as a prognostic marker in operable non-small cell lung cancer. Ann Thorac Surg 65: 1405-1409

Mattern J (2001) Role of angiogenesis in drug resistance. Anticancer Res 21(6B): $4265-4270$

Mattern J, Koomägi R, Volm M (1995) Vascular endothelial growth factor expression and angiogenesis in non-small cell lung carcinomas. Int $J$ Oncology 6: 1059-1062

Meert AP, Berghmans T, Branle F, Lemaitre F, Mascaux C, Rubesova E, Vermylen P, Paesmans M, Sculier JP (1999) Phase II and III studies with new drugs for non-small cell lung cancer: a systematic review of the literature with a methodology quality assessment. Anticancer Res 19: 4379-4390

Meert AP, Paesmans M, Berghmans T, Martin B, Mascaux C, Vallot F, Verdebout JM, Lafitte JJ, Sculier JP (2001) Prophylactic cranial irradiation in small cell lung cancer: a systematic review of the literature with metaanalysis. BMC Cancer 1: 5

Mulrow CD (1987) The medical review article: state of the science. Ann Intern Med 106: $485-488$

O’Byrne KJ, Koukourakis MI, Giatromanolaki A, Cox G, Turley H, Steward WP, Gatter K, Harris AL (2000) Vascular endothelial growth factor, platelet-derived endothelial cell growth factor and angiogenesis in non-smallcell lung cancer. Br J Cancer 82: 1427-1432

Offersen BV, Pfeiffer P, Hamilton-Dutoit S, Overgaard J (2001) Patterns of angiogenesis in nonsmall-cell lung carcinoma. Cancer 91: 1500-1509

Ohta Y, Tomita Y, Oda M, Watanabe S, Murakami S, Watanabe Y (1999) Tumor angiogenesis and recurrence in stage I non-small cell lung cancer. Ann Thorac Surg 68: 1034-1038

Paesmans M, Sculier JP (1998) Les facteurs pronostiques. In: Cancers bronchopulmonaires, Milleron B, Depierre A (eds). pp 239-247. Arnette: VélizyVillacoublay
Parmar MK, Torri V, Stewart L (1998) Extracting summary statistics to perform meta-analyses of the published literature for survival endpoints. Stat Med 17: 2815-2834

Pastorino U, Andreola S, Tagliabue E, Pezella F, Incarbone E, Sozzi G, Buyse M, Menard S, Pierotti M, Rilke F (1997) Immunocytochemical markers in stage I lung cancer: relevance to prognosis. J Clin Oncology 15: 2858 - 2865

Pazouki S, Chisholm DM, Adi MM, Carmichael G, Farquharson M, Ogden GR, Schor SL, Schor AM (1997) The association between tumour progression and vascularity in the oral mucosa. J Pathol 183: 39-43

Sheng HY, Aoe M, Doihara H, Andou A, Shimizu N (2000) Prognostic value of vascular endothelial growth factor expression in primary lung carcinoma. Acta Med Okayama 54: 119-126

Shibusa T, Shijubo N, Abe S (1998) Tumor angiogenesis and vascular endothelial growth factor expression in stage I lung adenocarcinoma. Clin Cancer Res 4: $1483-1487$

Steels E, Paesmans M, Berghmans T, Branle F, Lemaitre F, Mascaux C, Meert AP, Vallot F, Lafitte JJ, Sculier JP (2001) Role of p53 as a prognostic factor for survival in lung cancer: a systematic review of the literature with a meta-analysis. Eur Respir J 18: $705-719$

Stewart LA, Parmar MK (1993) Meta-analysis of the literature or of individual patient data: is there a difference?. Lancet 341: 418-422

Strauss GM (1997) Prognostic markers in resectable non-small cell lung cancer. Oncol Clin North Am 11: 409-434

Takanami I, Takeuchi K, Kodaira S (1999) Tumor-associated macrophage infiltration in pulmonary adenocarcinoma: association with angiogenesis and poor prognosis. Oncology 57: 138-142

Takanami I, Takeuchi K, Naruke M (2000) Mast cell density is associated with angiogenesis and poor prognosis in pulmonary adenocarcinoma. Cancer 88: $2686-2692$

Takanami I, Tanaka F, Hashizume T, Kodaira S (1997) Tumor angiogenesis in pulmonary adenocarcinomas: relationship with basic fibroblast growth factor, its receptor, and survival. Neoplasma 44: 295-298

Tanigawa N, Amaya $\mathrm{H}$, Matsumura $\mathrm{M}$, Shimomatsuya T, Horiuchi $\mathrm{T}$, Muraoka R, Iki M (1996) Extent of tumor vascularization correlates with prognosis and hematogenous metastasis in gastric carcinomas. Cancer Res 56: $2671-2676$

Vermeulen PB, Gasparini G, Fox SB, Toi M, Martin L, McCulloch P, Pezzella F, Viale G, Weidner N, Harris AL, Dirix LY (1996) Quantification of angiogenesis in solid human tumours: an international consensus on the methodology and criteria of evaluation. Eur J Cancer 32A: 2474-2484

Vermeulen PB, Libura M, Libura J, O’Neill PJ, van Dam P, Van Marck E, Van Oosterom AT, Dirix LY (1997) Influence of investigator experience and microscopic field size on microvessel density in node-negative breast carcinoma. Breast Cancer Res Treat 42: 165-172

Weidner N, Folkman J, Pozza F, Bevilacqua P, Allred EN, Moore DH, Meli S, Gasparini G (1992) Tumor angiogenesis: a new significant and independent prognostic indicator in early-stage breast carcinoma. J Natl Cancer Inst 84: $1875-1887$

Weidner N, Semple JP, Welch WR, Folkman J (1991) Tumor angiogenesis and metastasis-correlation in invasive breast carcinoma. $N$ Engl J Med 324: $1-8$

Yamazaki K, Abe S, Takewara H, Sukoh N, Watanabe N, Ogura S, Nakajima I, Isobe H, Inoue K, Kawakami Y (1994) Tumor angiogenesis in human lung adenocarcinoma. Cancer 74: 2245-2250

Yano T, Tanikawa S, Fujie T, Masutani M, Horie T (2000) Vascular endothelial growth factor expression and neovascularisation in non-small cell lung cancer. Eur J Cancer 36: 601-609

Yusuf S, Peto R, Lewis J, Collins R, Sleight P (1985) Beta blockade during and after myocardial infarction: an overview of the randomized trials. Prog Cardiovasc Dis 27: $335-371$ 